\title{
Posture Analysis of Various Types of Crutch Gait of Healthy Volunteers
}

\author{
JeOng-Uk Lee, PT, MS ${ }^{1)}$, Ju-Hyun Kim, PT, MS ${ }^{1)}$, Lim-Kyu Lee, PT, MS ${ }^{1)}$, \\ Mee-Young Kim, PT, MS ${ }^{1)}$, Seung-Min Yang, PT, MS'1), Tae-Hyun Lee, PhD ${ }^{2)}$, \\ JUNGHWAN KIM, PT, PhD ${ }^{3)^{*}}$ \\ 1) Laboratory of Health Science and Nanophysiotherapy, Department of Physical Therapy, Graduate \\ School, Yongin University \\ 2) Department of Combative Martial Arts Training, College of Martial Arts, Yongin University \\ 3) Department of Physical Therapy, College of Public Health and Welfare, Yongin University: Yongin \\ 449-714, Korea. TEL: +82 31-8020-2771, FAX: +82 31-8020-3075
}

\begin{abstract}
Purpose] Posture analysis has been used widely as a tool for gait evaluation. However, previous research on posture analysis has not considered the various types of crutch gait. The purpose of this study was to investigate the body posture of the non-crutch gait and types of crutch gait of healthy volunteers. [Methods] Using gait and position assessment equipment, the present study analysed the posture of healthy adult subjects in the superior view, anterior view, and lateral view during non-crutch gait, swing to crutch gait, swing through crutch gait, two-point crutch gait, and four-point crutch gait. [Results] In superior views, the angle of the shoulder area significantly increased in the negative direction at the starting position compared to the normal standing position. In anterior views, the angle of the shoulder and hand areas significantly decreased from the positive direction to the negative direction at the starting position compared to the normal position. In lateral views, the angle of the neck area significantly decreased in the negative direction at the starting position compared to the normal standing position. [Conclusion] These results demonstrate that body posture changed according to the type of crutch gait used by the healthy volunteers.
\end{abstract}

Key words: Posture analysis, Various types of crutch gait, Healthy volunteers

(This article was submitted Oct. 24, 2012, and was accepted Dec. 4, 2012)

\section{INTRODUCTION}

Assistive devices, such as canes, crutches, and walkers, are commonly recommended for problems of pain, fatigue, equilibrium, joint instability, muscular weakness, excessive skeletal loading, and cosmesis ${ }^{1}$. Assistive devices are also used for the functional recovery of locomotion. Damage and disability accompanied by low extremity pain might result in gait disturbance ${ }^{2}$. Many assistive devices can ameliorate gait disturbance. The most commonly used assistive devices are axillary crutches for reducing the amount of weight placed on the disabled extremity ${ }^{3-6)}$. Crutches help an individual maintain balance and can help relieve pain in the hip, knee, ankle, or foot ${ }^{7-10)}$. Crutch gait patterns include twopoint, three-point, four-point, swing-to, and swing-through patterns ${ }^{5,7)}$. Four-point gait is the slowest and the most stable gait type, and two-point gait, which is similar to normal gait pattern, is the second slowest gait type ${ }^{5,7)}$. Changes to the body posture, foot pressure, and joint posture occur according to the crutch gait pattern ${ }^{11-13)}$. Crutches cause the subject to tilt forward, which changes the body posture and joint positions of the hand, elbow, shoulder, and trunk in the stance phase ${ }^{12-14)}$. Due to the rapid development of modern

*To whom correspondence should be addressed.

E-mail: junghwankim3@yongin.ac.kr civilization, advances in science and medicine have prolonged human lives. Maintaining the quality of life results in people who are happier and healthier, and therefore quality of life is a prerequisite for the aging process. Posture is an important health indicator, and postural abnormalities are associated with a large number of disorders, including pain syndromes, generalized or regional musculoskeletal disorders, and respiratory dysfunctions ${ }^{15-17)}$. Furthermore, body posture is important in the function of the musculoskeletal system. Starting movement and maintaining equilibrium involve a complex of sensory and motor controls. Clinically, abnormal alignment of the body posture is related to a variety of diseases ${ }^{18)}$. Lower extremity alignment has been proposed as a risk factor of acute and chronic lower extremity injuries, including patellofemoral syndrome, anterior cruciate ligament injuries, medial tibial stress syndrome, stress fractures, and plantar fasciitis. It has been suggested that biomechanical changes resulting from abnormal alignment may influence joint loads, the mechanical efficiency of muscles, and proprioceptive orientation and feedback from the hip and knee, resulting in altered neuromuscular function and control of the lower extremities. The alignment of the lower extremities is associated with navicular drop, tibial varum, quadriceps angle, genu recurvatum, anterior pelvic tilt, and femoral anteversion ${ }^{19-21)}$. Many studies have focused on the lower extremities in a static posture, but did 
not include crutch gait analysis. Understanding the biomechanics of crutch gait could prevent damage occurring during crutch gait, and assist in the adoption of efficient gait with the correct use of crutches. Therefore, this study investigated the posture analysis of non-crutch gait in the static position and types of crutch gait of healthy volunteers.

\section{SUBJECTS AND METHODS}

The present study was conducted in March 2009 with 12 male and 11 female subjects. The subjects were informed about the intent of the study before they agreed to participate. The subjects were free of: musculoskeletal diseases that affected the upper extremities, lower extremities or abnormal gaits, such as those arising from neurosurgical or orthopedic damage; lesions of the spine or past histories of surgery; abnormalities of gait, such as limping; structural abnormalities of the legs or feet; corns or calluses on the feet; diplopia, visual field defects or abnormalities in the vestibular organs. The mean age of the subjects who participated in the study was $26.7 \pm 1.5$ years. Their mean height was $167.4 \pm 8.9 \mathrm{~cm}$, and their mean weight was 62.2 $\pm 9.9 \mathrm{~kg}$. Each subject was provided with a crutch of length and handle position that were suitable for the subject's height. The humeral crosspieces of the crutches were located $5 \mathrm{~cm}$ below the upper extremity axillary boundary, the handles were located within reach of the hand when the elbow joint was bent to $20^{\circ}-30^{\circ}$, and the length of each crutch was adjusted so that the end of the crutch could be comfortably placed $15 \mathrm{~cm}$ ahead on the ground lateral to the top of the fifth metatarsal bone ${ }^{11,22)}$. The subjects were given instruction about how to use the crutches and types of crutch gait before they were measured. The subjects' body posture was measured using a gait and position assessment (GPA) system. Although other equipment, such as X-rays and electrogoniometers are also useful for position measurement, there are issues concerning their use ${ }^{23)}$. X-rays are economical, convenient, and easily readable for direct visualization of anatomies. However, X-ray imaging involves radioactivity, which is harmful to humans ${ }^{24}$. Moreover, electrogoniometers are inconvenient because the tester must measure each position repeatedly. However, GPA is advantageous because it can be used to measure the positions of patients for whom X-ray imaging is not possible, and it can improve subjects' understanding of their posture. The structure of the GPA consists of a wall, a superior camera, a lateral camera, and an anterior camera. The wall is $1 \mathrm{~mm}$ wide, $50 \mathrm{~cm}$ long and $2.5 \mathrm{~m}$ high. Each subject was instructed to stand in front of the wall in a static crutch gait position. The position was measured in three views: the superior view, the anterior view, and the lateral view. All measurements were performed by one physical therapist only. Normal standing positions were measured for the non-crutch, starting position before using a crutch to perform swing to crutch gait, swing through crutch gait, two-point crutch gait (right and left), and four-point crutch gait (right and left) (Fig. 1). The acromion of both shoulders and the top surfaces of both ears were measured in the superior view. The acromion of both shoulders, the ends of both hands, the areas from the center of the patellas to the ankle joints, and the area from

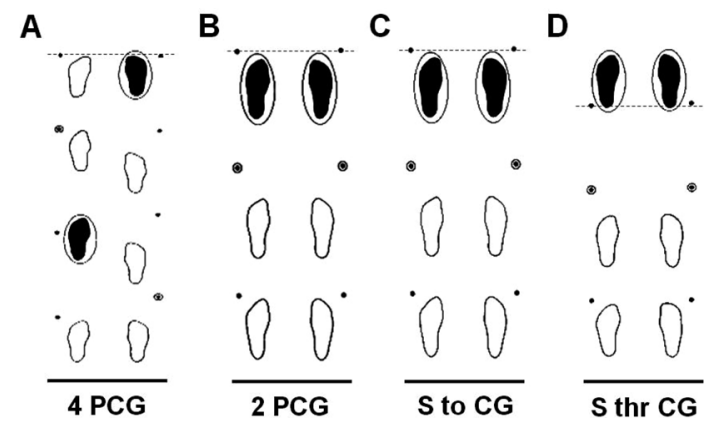

Fig. 1. Schematic representation of the experimental methods for measuring the types of crutch gait For the analysis of body posture, types of crutch gait such as four-point (A), two-point (B), swing to (C), and swing through gait (D) were measured using gait and position assessment (GPA).

4 PCG, four-point crutch gait; 2 PCG, twopoint crutch gait; $S$ to $C G$, swing to crutch gait; $\mathrm{S}$ thr CG, swing through crutch gait.

the glabella to the philtrum on the face were measured in the anterior view. The area from the external auditory meatus to the center of the central fiber of the deltoid muscle was measured in the lateral view. The angles of individual body areas were measured to analyze the posture in relation to the type of crutch gait. This study used SPSS (version 12.0) for the statistical analysis and calculation of means and standard deviations. Repeated one-way ANOVA ( $\alpha=$ 0.05 ) was used to test the statistical significance of differences within each comparison group. The Bonferroni test method was used as a posthoc test of the statistical significance of differences between comparison groups. Each difference was considered statistically significant when the $p$ value was smaller than 0.05 . The protocol for the study was approved by the Committee of Ethics in Research of the University of Yongin, in accordance with the terms of Resolution 5-1-20, December 2006.

\section{RESULTS}

In superior views, the angle of the shoulder area significantly increased in the negative direction in the starting position with a crutch compared to the normal standing position. In anterior views, the angle of the shoulder area significantly changed from the positive direction to the negative direction in the starting position compared to the normal standing position. In lateral views, the angle of the neck area significantly decreased in the negative direction in the starting position compared to the normal standing position (Fig. 2) (Table 1). Compared to the normal standing position, the angle of the shoulder area significantly changed from the negative direction to the positive direction in the starting position of the two-point crutch gait (right), and significantly increased in the negative direction the two-point crutch gait (left) in superior views. In addition, the shoulder area angle showed significant differences 
A.

a)

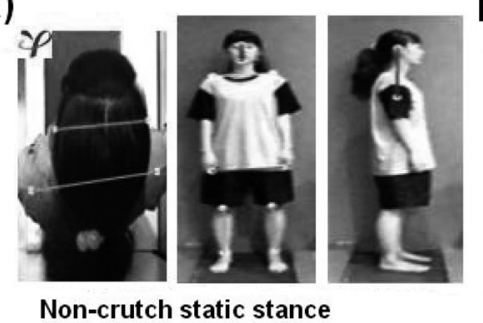

B. Right Side

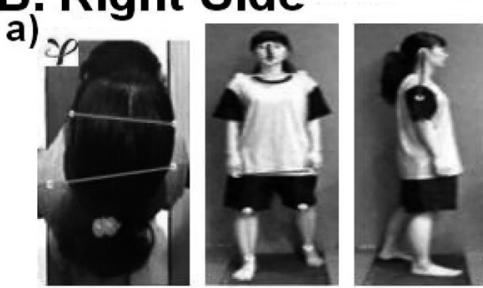

Non-crutch dynamic stance

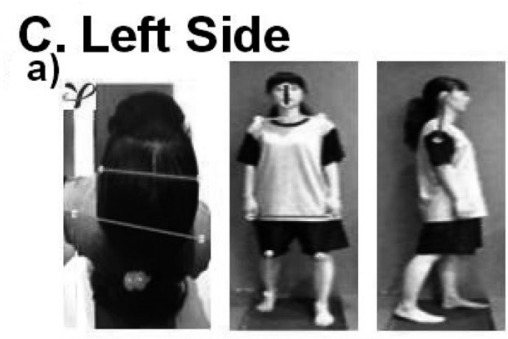

Non-crutch dynamic stance b)

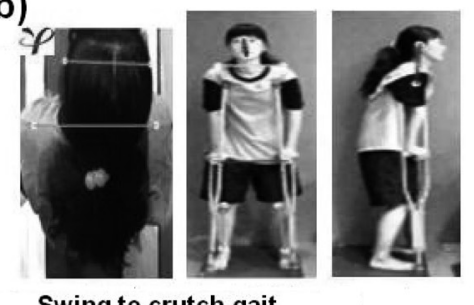

Swing to crutch gait

b)

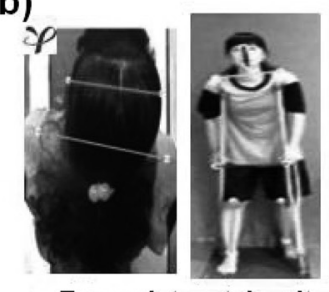

Two-point crutch gait

b)
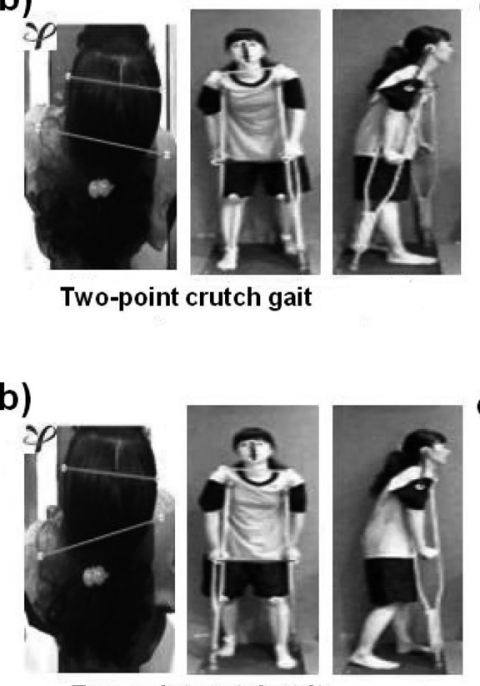

c)

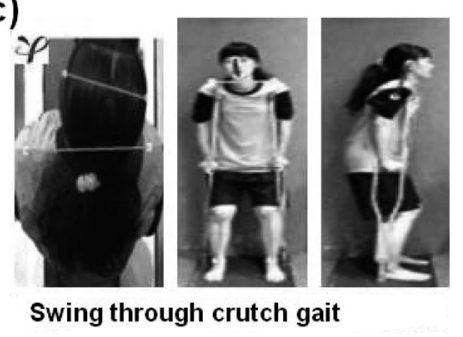

c)

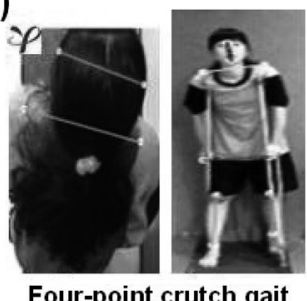

Four-point crutch gait

c)

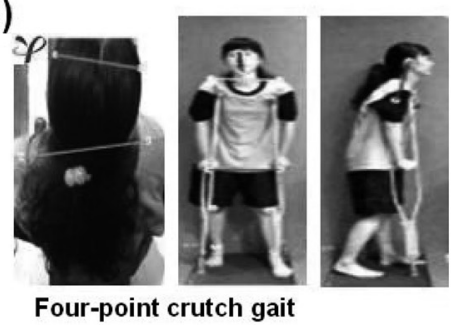

Fig. 2. Measurements of normal standing position and various types of crutch gait

In this study, subjects were measured using a Gait and Posture Assesment to evaluate the alignment of the body. This system consist of a wall (length, width, and height of $0.5 \times 1 \times 2.5 \mathrm{~m}$ ) and superior, anterior, and lateral view cameras. All measurement were performed by the same physical therapist. Measurement was made of three views: the superior view (both sides of the shoulder acromion, and both sides of the ear upper surface), the anterior view (both sides of the shoulder acromion, both sides of the hand tip, both knees from the patellar center to the ankle joint, and from the facial glabellar to philtrum), and the lateral view (from the external auditory meatus to the deltoid middle fiber center).

Table 1. Analysis of the normal standing position and starting position with a crutch

\begin{tabular}{|c|c|c|c|c|c|c|}
\hline \multirow{2}{*}{\multicolumn{2}{|c|}{ Angle $\left(^{\circ}\right)$}} & \multicolumn{2}{|c|}{ Normal standing position } & \multicolumn{2}{|c|}{ Starting position with a crutch } & \multirow{3}{*}{$\frac{p \text {-value }}{0.001^{* *}}$} \\
\hline & & \multirow{2}{*}{$\begin{array}{l}\text { Mean } \\
-2.72\end{array}$} & \multirow{2}{*}{$\begin{array}{c}\text { SE } \\
0.70\end{array}$} & \multirow{2}{*}{$\begin{array}{l}\text { Mean } \\
-0.11\end{array}$} & \multirow{2}{*}{$\begin{array}{c}\text { SE } \\
0.15\end{array}$} & \\
\hline $\mathrm{Sv}$ & Shoulder & & & & & \\
\hline \multirow{6}{*}{$\mathrm{Av}$} & Ear/shoulder & -2.21 & 0.67 & -1.43 & 0.28 & NS \\
\hline & Shoulder & -2.53 & 0.60 & 1.26 & 0.39 & $0.000 * * *$ \\
\hline & Hand & -2.47 & 0.39 & 0.18 & 0.26 & $0.000^{* * *}$ \\
\hline & Rt knee & 0.18 & 0.57 & 0.16 & 0.32 & NS \\
\hline & Lt knee & -2.45 & 0.55 & -0.63 & 0.43 & $0.027 *$ \\
\hline & Head & 2.77 & 0.38 & 0.99 & 0.51 & $0.021^{*}$ \\
\hline Lv & Neck & -5.60 & 0.72 & -24.03 & 1.18 & $0.000 * * *$ \\
\hline
\end{tabular}

$* \mathrm{p}<0.05, * * \mathrm{p}<0.01, * * * \mathrm{p}<0.001$. Sv, superior view; Av, anterior view; Lv, lateral view; SP, starting position; NS, not significant.

between the two-point crutch gait (right) and the two-point crutch gait (left). In anterior views, the angle of the shoulder area significantly changed from the positive direction to the negative direction in the starting position of the two-point crutch gait (right). In lateral views, the angle of the neck area significantly decreased in the negative direction in the 
Table 2. Analysis of the starting position and two point crutch gait (Rt and Lt)

\begin{tabular}{|c|c|c|c|c|c|c|c|c|}
\hline & \multirow[t]{2}{*}{ Angle $\left(^{\circ}\right)$} & \multicolumn{2}{|c|}{ Starting position } & \multicolumn{2}{|c|}{$\begin{array}{l}\text { Two point crutch } \\
\text { gait(Rt) }\end{array}$} & \multicolumn{2}{|c|}{$\begin{array}{l}\text { Two point crutch } \\
\text { gait }(\mathrm{Lt})\end{array}$} & \multirow[b]{2}{*}{ Post hoc } \\
\hline & & Mean & SE & Mean & SE & Mean & SE & \\
\hline \multirow[t]{2}{*}{ Sv } & Shoulder & -0.11 & 0.15 & 3.68 & 0.80 & -8.63 & 0.93 & $\mathrm{SP}^{* *}-\mathrm{TPR}^{* *}, \mathrm{SP}^{* * *}-\mathrm{TPL}^{* * *}, \mathrm{TPR}^{* * *}-\mathrm{TPL}^{* * *}$ \\
\hline & Ear/shoulder & -1.43 & 0.28 & 3.19 & 1.32 & -5.47 & 1.73 & $\mathrm{SP}^{*}$-TPR*,TPR $* * *-\mathrm{TPL}^{* * *}$ \\
\hline \multirow[t]{5}{*}{ Av } & Shoulder & 1.26 & 0.34 & -2.02 & 0.97 & -0.77 & 0.79 & SP*-TPR* \\
\hline & Hand & 0.18 & 0.26 & 1.12 & 0.63 & -2.64 & 0.52 & $\mathrm{SP}^{* * *}$-TPL ${ }^{* * *}, \mathrm{TPR}^{* * *}$-TPL ${ }^{* * *}$ \\
\hline & Rt knee & 0.16 & 0.32 & -3.17 & 0.63 & 3.72 & 0.86 & $\mathrm{SP}^{* * *}-\mathrm{TPR}^{* * *}, \mathrm{SP} * *-\mathrm{TPL}^{* *}, \mathrm{TPR}^{* * *}-\mathrm{TPL}^{* * *}$ \\
\hline & Lt knee & -0.63 & 0.43 & 0.20 & 0.83 & -4.87 & 0.58 & $\mathrm{SP}^{* * *}$-TPL ${ }^{* * *}, \mathrm{TPR}^{* * *}$-TPL ${ }^{* * *}$ \\
\hline & Head & 0.99 & 0.51 & 1.67 & 0.58 & 4.56 & 0.74 & $\mathrm{SP}^{* *}$-TPL**,TPR*-TPL* \\
\hline Lv & Neck & -24.03 & 1.18 & -19.39 & 1.20 & -8.42 & 1.81 & $\mathrm{SP}^{* * *}-\mathrm{TPL}^{* * *}, \mathrm{TPR}{ }^{* * *}-\mathrm{TPL} * * *$ \\
\hline
\end{tabular}

$* \mathrm{p}<0.05, * * \mathrm{p}<0.01,{ }^{* * *} \mathrm{p}<0.001$. Sv, superior view; Av, anterior view; Lv, lateral view; SP, starting position; TPR, two point crutch gait (Rt, right); TPL, two point crutch gait (Lt, left); NS, not significant.

Table 3. Analysis of the starting position and four-point crutch gait (Rt and Lt)

\begin{tabular}{|c|c|c|c|c|c|c|c|c|}
\hline & \multirow[t]{2}{*}{ Angle $\left(^{\circ}\right)$} & \multicolumn{2}{|c|}{ Starting position } & \multicolumn{2}{|c|}{$\begin{array}{l}\text { Four point crutch } \\
\text { gait (Rt) }\end{array}$} & \multicolumn{2}{|c|}{$\begin{array}{l}\text { Four point crutch } \\
\text { gait }(L t)\end{array}$} & \multirow[b]{2}{*}{ Post hoc } \\
\hline & & Mean & SE & Mean & SE & Mean & SE & \\
\hline \multirow[t]{2}{*}{$\mathrm{Sv}$} & Shoulder & -0.11 & 0.15 & 3.61 & 1.03 & -8.46 & 1.31 & $\mathrm{SP}^{* *}$-FPR ${ }^{* *}, \mathrm{SP}^{* * *}$-FPL ${ }^{* * *}, \mathrm{FPR}^{* * *}$-FPL ${ }^{* * *}$ \\
\hline & Ear/shoulder & -1.43 & 0.28 & 3.54 & 1.12 & -4.94 & 1.81 & $\mathrm{SP}^{* *}$-FPR**,FPR**-FPL** \\
\hline \multirow[t]{5}{*}{ Av } & Shoulder & 1.26 & 0.34 & -3.16 & 0.84 & -0.97 & 0.63 & $\mathrm{SP}^{* * *}$-FPR***,SP*-FPL* \\
\hline & Hand & 0.18 & 0.26 & 0.88 & 0.69 & -2.23 & 0.47 & $\mathrm{SP}^{* *}$-FPL**,FPR*-FPL* \\
\hline & Rt knee & 0.16 & 0.32 & -3.78 & 0.66 & 4.09 & 0.78 & $\mathrm{SP}^{* * *}{ }_{-} \mathrm{FPR}^{* * *}, \mathrm{SP}^{* *}{ }_{-} \mathrm{FPL}^{* *}, \mathrm{FPR}^{* * *}{ }_{-} \mathrm{FPL}^{* * *}$ \\
\hline & Lt knee & -0.63 & 0.43 & 0.58 & 0.76 & -5.12 & 0.62 & $\mathrm{SP}^{* * *}$-FPL***,FPR ${ }^{* * *}$-FPL ${ }^{* * *}$ \\
\hline & Head & 0.99 & 0.51 & 2.25 & 0.68 & 4.07 & 0.65 & $\mathrm{SP}^{* *}$-FPL** \\
\hline $\mathrm{Lv}$ & Neck & -24.03 & 1.18 & -20.07 & 1.40 & -8.54 & 1.67 & $\mathrm{SP}^{* * *}$-FPL ${ }^{* * *}, \mathrm{FPR}^{* * *}$-FPL ${ }^{* * *}$ \\
\hline
\end{tabular}

$* \mathrm{p}<0.05, * * \mathrm{p}<0.01, * * * \mathrm{p}<0.001$. Sv, superior view; Av, anterior view; Lv, lateral view; SP, starting position; FPR, four point crutch gait (Rt); FPL, four point crutch gait (Lt); NS, not significant.

starting position of the two-point crutch gait (left). The neck area angle showed significant differences between the twopoint crutch gait (right) and the two-point crutch gait (left) (Fig. 2) (Table 2). Furthermore, the angle of the shoulder area significantly changed from the negative direction to the positive direction in the starting position of the four-point crutch gait (right), and significantly increased in the negative direction of the four-point crutch gait (left) in superior views. In addition, the shoulder area angle showed significant differences between the four-point crutch gait (right) and the four-point crutch gait (left). In anterior views, the angle of the shoulder area significantly changed from the positive direction to the negative direction in the starting position of the four-point crutch gait (right) and the fourpoint crutch gait (left). Furthermore, in lateral views, the angle of the neck area significantly decreased in the negative direction in the starting position of the four-point crutch gait (left), and showed significant differences between the four-point crutch gait (right) and the four-point crutch gait (left) (Fig. 2) (Table 3). Meanwhile, in superior views, the angle of the shoulder area significantly changed from the negative direction to the positive direction in the starting position of the swing through crutch gait. In anterior views, the angle of the shoulder area significantly changed from the positive direction to the negative direction in the start- ing position of the swing to crutch gait and swing through crutch gait. In lateral views, the angle of the neck area significantly decreased in the negative direction in the starting position of the swing to crutch gait and swing through crutch gait (Fig. 2) (Table 4).

\section{DISCUSSION}

This study performed an analysis of posture of types of crutch gait in the static position. Previous studies have not considered the various types of crutch gait in posture analysis. In this study, the crutch gait positions of healthy adults were analyzed by type using superior, anterior, and lateral views. The results show clear differences among the types of crutch gait in static positions, which were analyzed in three different views. In a previous study, the posture analysis of lower extremities (quadriceps angle, genu recurvatum, anterior pelvic tilt, femoral anteversion, navicular drop, tibial varum) showed no significant differences between normal male/female adults and male/female athletes ${ }^{21)}$. Similarly, the present study found no significant differences between the male and female subjects. In a study that analyzed the gaits of persons who were wearing gait assisters with flat shoe soles and those who were wearing gait assisters with slightly bent shoe soles, signifi- 
Table 4. Analysis of the starting position, swing to crutch gait, and swing through crutch gait

\begin{tabular}{|c|c|c|c|c|c|c|c|c|}
\hline & \multirow[t]{2}{*}{ Angle $\left(^{\circ}\right)$} & \multicolumn{2}{|c|}{$\begin{array}{l}\text { Starting } \\
\text { position }\end{array}$} & \multicolumn{2}{|c|}{$\begin{array}{l}\text { Swing to } \\
\text { crutch gait }\end{array}$} & \multicolumn{2}{|c|}{$\begin{array}{l}\text { Swing through } \\
\text { crutch gait }\end{array}$} & \multirow[b]{2}{*}{ Post hoc } \\
\hline & & Mean & $\mathrm{SE}$ & Mean & SE & Mean & SE & \\
\hline \multirow[t]{2}{*}{$\mathrm{Sv}$} & Shoulder & -0.11 & 0.15 & -1.49 & 0.59 & -1.58 & 0.46 & SP*-STH* \\
\hline & Ear/shoulder & -1.43 & 0.28 & -0.47 & 1.18 & -0.58 & 1.11 & NS \\
\hline \multirow[t]{5}{*}{ Av } & Shoulder & 1.26 & 0.34 & -1.95 & 0.58 & -2.18 & 0.47 & $\mathrm{SP}^{* * *}-\mathrm{ST}^{* * *}, \mathrm{SP}^{* * *}-\mathrm{STH}^{* * *}$ \\
\hline & Hand & 0.18 & 0.26 & -0.79 & 0.28 & -1.64 & 0.34 & $\mathrm{SP}^{* *}-\mathrm{STH}^{* *}, \mathrm{ST}^{*}-\mathrm{STH}^{*}$ \\
\hline & Rt knee & 0.16 & 0.32 & 1.37 & 0.79 & -2.27 & 0.69 & $\mathrm{SP}^{*}-\mathrm{STH}^{*}, \mathrm{ST}^{* * *}-\mathrm{STH}^{* * *}$ \\
\hline & Lt knee & -0.63 & 0.43 & -2.77 & 0.68 & -4.67 & 0.73 & $\mathrm{SP}^{* *}-\mathrm{STH}^{* *}, \mathrm{ST}^{*}-\mathrm{STH}^{*}$ \\
\hline & Head & 0.99 & 0.51 & 3.33 & 0.54 & 3.94 & 0.58 & $\mathrm{SP}^{*}-\mathrm{ST}^{*}, \mathrm{SP}^{*}-\mathrm{STH}^{*}$ \\
\hline $\mathrm{Lv}$ & Neck & -24.03 & 1.18 & -13.13 & 1.88 & -16.35 & 1.67 & $\mathrm{SP}^{* * *}{ }_{-} \mathrm{ST}^{* * *}, \mathrm{SP}^{* *}{ }_{-} \mathrm{STH}^{* *}$ \\
\hline
\end{tabular}

cant differences were reported in the dorsal flexion of the ankle and gait velocity which were related to the degrees of flatness and bend of the shoe soles ${ }^{25)}$. Gait velocity would increase if the shoe soles of crutch walkers had bent heels to facilitate heel strikes during four-point crutch gait, which is slow but the safest for persons using crutches. A comparative study that analyzed gait and exercises performed by stroke patients, using a stick and a tool called TheraTogs, found that the latter tool maintained symmetric body positions, thus providing better outcomes for gait and motor ability $^{26)}$. However, since only one side of the body is used when a stick is employed, TheraTogs was more efficient than a stick in terms of symmetry of position, which is also the case with crutches. If only one crutch is used, the body position is easily distorted. The use of two crutches helps maintain a balanced body position. A study that analyzed the gait of 20 normal persons and 46 diabetes patients reported that the diabetes patients had shorter strides, took longer to switch between the stance and swing phases, and showed reduced stability when initiating movement in the standing position. However, although trunk abduction-adduction, trunk flexion-extension, hip abduction-adduction, hip internal-external rotation, knee flexion-extension, ankle internal-external rotation, and ankle flexion-extension showed significant differences between the normal persons and diabetes patients, trunk internal-external rotation and ankle abduction-adduction did not show any significant differences ${ }^{27)}$. Similarly, in the present study, when the starting position of four-point crutch gait with low velocity was compared with that of swing through crutch gait with high velocity, significant differences were shown in the superior, anterior, and lateral views. It is commonly accepted that if force is repeatedly applied to the anterior region of the hip joint in activities such as running, pain may occur in the hip joint and the inguinal area. This pain occurs because the hip joint receives the largest load during the switch between the stance and swing phases ${ }^{28)}$. The present study showed that because the use of crutches reduced the weight imposed on the hip joint, repeated stress imposed on this joint could be effectively reduced in crutch gait. Thus, the use of crutches could be effective at reducing pain in the hip joint or the inguinal area.

\section{REFERENCES}

1) Smidt GL, Mommens MA: System of reporting and comparing influence of ambulatory aids on gait. Phys Ther, 1980, 60: 551-558. [Medline]

2) Williamson VC: Management of lower extremity fractures. Orthop Nurs, 1998, 17: 84-87. [Medline] [CrossRef]

3) Van Hook FW, Demonbreum D, Weiss BD: Ambulatory devices for chronic gait disorders in the elderly. Am Fam Physician, 2003, 67: 1717-1724. [Medline]

4) Goh JC, Toh SL, Bose K: Biomechanical study on axillary crutches during single-leg swing-through gait. Prosthet Orthot Int, 1986, 10: 89-95. [Medline]

5) Lane PL, LeBlanc R: Crutch walking. Orthop Nurs, 1990, 9: 31-38. [Medline] [CrossRef]

6) Westerhoff P, Graichen F, Bender A, et al.: In vivo measurement of shoulder joint loads during walking with crutches. Clin Biomech (Bristol, Avon), 2012, 27: 711-718. [Medline] [CrossRef]

7) Li S, Armstrong CW, Cipriani D: Three-point gait crutch walking: variability in ground reaction force during weight bearing. Arch Phys Med Rehabil, 2001, 82: 86-92. [Medline] [CrossRef]

8) Bailey CA, Martin T, Keene GC: The use of an axillary crutch as a knee flexion contracture correction device. Ann R Coll Surg Engl, 2009, 91: 170. [Medline]

9) Youdas JW, Kotajarvi BJ, Padgett DJ, et al.: Partial weight-bearing gait using conventional assistive devices. Arch Phys Med Rehabil, 2005, 86: 394-398. [Medline] [CrossRef]

10) Clark BC, Manini TM, Ordway NR, et al.: Leg muscle activity during walking with assistive devices at varying levels of weight bearing. Arch Phys Med Rehabil, 2004, 85: 1555-1560. [Medline] [CrossRef]

11) Lee JU, Kim MY, Kim JH, et al.: Analysis of plantar foot pressure during the non-crutch, two-point, and four-point crutch gait performed by healthy volunteers. J Phys Ther Sci, 2011, 23: 489-493. [CrossRef]

12) Kang JH, Park RY, Lee SJ, et al.: The effect of the forward head posture on postural balance in long time computer based worker. Ann Rehabil Med, 2012, 36: 98-104. [Medline] [CrossRef]

13) Endo K, Suzuki H, Nishimura H, et al.: Sagittal lumbar and pelvic alignment in the standing and sitting positions. J Orthop Sci, 2012.

14) Bajd T, Kralj A, Zefran M: Unstable states in four-point walking. J Biomed Eng, 1993, 15: 159-162. [Medline] [CrossRef]

15) Ferreira EA, Duarte M, Maldonado EP, et al.: Postural assessment software (PAS/SAPO): validation and reliabiliy. Clinics (Sao Paulo), 2010, 65: 675-681. [Medline] [CrossRef]

16) Chanplakorn P, Sa-Ngasoongsong P, Wongsak S, et al.: The correlation between the sagittal lumbopelvic alignments in standing position and the risk factors influencing low back pain. Orthop Rev Pavia, 2012, 4: e11. [Medline]

17) Teichtahl AJ, Wluka AE, Strauss BJ, et al.: The associations between body and knee height measurements and knee joint structure in an asymptomatic cohort. BMC Musculoskelet Disord, 2012, 13: 19. [Medline] [CrossRef]

18) Moya GB, Siqueira CM, Caffaro RR, et al.: Can quiet standing posture predict compensatory postural adjustment? Clinics (Sao Paulo), 2009, 64: 791-796. [Medline] [CrossRef]

19) Nguyen AD, Shultz SJ: Identifying relationships among lower extrem- 
ity alignment characteristics. J Athl Train, 2009, 44: 511-518. [Medline] [CrossRef]

20) Nguyen AD, Boling MC, Levine B, et al.: Relationships between lowe extremity alignment and the quadriceps angle. Clin J Sport Med, 2009, 19: 201-206. [Medline] [CrossRef]

21) Medina McKeon JM, Hertel J: Sex differences and representative values for 6 lower extremity alignment measures. J Athl Train, 2009, 44: 249-255. [Medline] [CrossRef]

22) Bauer DM, Finch DC, McGough KP, et al.: A comparative analysis of several crutch-length-estimation techniques. Phys Ther, 1991, 71: 294-300. [Medline]

23) Normand MC, Descarreaux M, Harrison DD, et al.: Three dimensional evaluation of posture in standing with the PosturePrint: an intra- and inter-examiner reliability study. Chiropr Osteopat, 2007, 15: 15. [Medline] [CrossRef]

24) Dewi DE, Veldhuizen AG, Burgerhof JG, et al.: Reproducibility of standing posture for X-ray radiography: a feasibility study of the BalancAid with healthy young subjects. Ann Biomed Eng, 2010, 38: 3237-3245.
[Medline] [CrossRef

25) Wang CC, Hansen AH: Response of able-bodied persons to changes in shoe rocker radius during walking: changes in ankle kinematics to maintain a consistent roll-over shape. J Biomech, 2010, 43: 2288-2293. [Medline] [CrossRef]

26) Maguire C, Sieben JM, Erzer F, et al.: How to improve walking, balance and social participation following stroke: a comparison of the long term effects of two walking aids-canes and an orthosis TheraTogs-on the recovery of gait following acute stroke. A study protocol for a multi-centre, single blind, randomised control trial. BMC Neurol, 2012, 12: 18. [Medline] [CrossRef]

27) Sawacha Z, Guarneri G, Avogaro A, et al.: A new classification of diabetic gait pattern based on cluster analysis of biomechanical data. J Diabetes Sci Technol, 2010, 4: 1127-1138. [Medline]

28) Lewis CL, Sahrmann SA, Moran DW: Effect of hip angle on anterior hip joint force during gait. Gait Posture, 2010, 32: 603-607. [Medline] [CrossRef] 